\title{
Putting the record straight on aprotinin as safe and effective: Results from a mixed treatment meta-analysis of trials of aprotinin
}

\author{
Neil Howell, PhD, FRCS(C-Th), ${ }^{\text {a,b }}$ Eshan Senanayake, MRCS, ${ }^{\text {a,b }}$ Nick Freemantle, $\mathrm{PhD},{ }^{\mathrm{c}}$ and \\ Domenico Pagano, MD, FRCS(C-Th) ${ }^{\text {a,b }}$
}

\begin{abstract}
Objective: Meta-analysis of small, randomized, placebo-controlled trials demonstrated efficacy and safety of aprotinin. After highly publicized retrospective studies and the early stopping of the Blood Conservation Using Antifibrinolytics in a Randomized Trial (BART), aprotinin was withdrawn. We conducted a new meta-analysis (including BART) on safety and efficacy of aprotinin in cardiac surgery.
\end{abstract}

\begin{abstract}
Methods: We conducted a mixed treatment comparisons network meta-analysis estimating the effects of aprotinin and alternative agents in reducing blood loss during surgery. We implemented a combination of direct and indirect evidence in mixed treatment comparisons and estimated relative effects for different agents on all-cause mortality and return to the operating room for bleeding and conducted a supportive analysis of the effects of different agents with only directly randomized trials.
\end{abstract}

Results: Mixed treatment analysis of 88 trials randomizing 15,528 patients to 1 of 3 antifibrinolytic agents demonstrated no difference in mortality between placebo and antifibrinolytic agents. Analysis of aprotinin versus tranexamic acid and $\varepsilon$-aminocaproic acid in 17 and 6 trials, respectively and tranexamic acid versus $\varepsilon$-aminocaproic acid in 5 trials demonstrated no difference in mortality between treatment allocations. All agents were superior to placebo in reducing reexploration for bleeding, with aprotinin numerically superior: aprotinin odds ratio, 2.6 (95\% confidence interval, 1.9-3.7); tranexamic acid odds ratio, 1.79 (1.2-2.9), and $\varepsilon$-aminocaproic acid odds ratio, 2.4 (1.3-6.6).

Conclusions: This mixed treatment comparisons meta-analysis demonstrates no increased mortality risk with aprotinin versus other antifibrinolytic agents. All agents were superior to placebo in reducing reexploration for bleeding after adult cardiac surgery. (J Thorac Cardiovasc Surg 2013;145:234-40)

The age and risk profile of patients undergoing cardiac surgery continue to increase. ${ }^{1}$ Such patients are at increased risk for significant postoperative bleeding necessitating transfusion of blood and blood products or further surgical intervention. ${ }^{2,3}$ Although modern treatments have resulted in similar early hospital mortalities between those who have significant bleeding problems and those who have not, this complication is still associated with significant resource utilization and could affect adversely late survival after surgery. ${ }^{3-5}$ Meta-analyses of antifibrinolytic agents has shown that they reduce the incidence of clinically significant bleeding, reducing both the need for transfusion and the need for surgical reexploration. ${ }^{6}$

Blood transfusion itself is not a hazard-free intervention, with the well-described risks of infectious disease

From the Department of Cardiac Surgery ${ }^{\mathrm{a}}$ and the School of Clinical and Experimental Medicine, ${ }^{\mathrm{b}}$ University Hospital Birmingham, Birmingham, UK; and the Department of Primary Care and Population Health, ${ }^{c}$ University College London, London, UK.

Disclosures: Authors have nothing to disclose with regard to commercial support. Received for publication Jan 24, 2012; revisions received June 8, 2012; accepted for publication July 10, 2012; available ahead of print Aug 13, 2012.

Address for reprints: Domenico Pagano, MD, FRCS(C-Th), FESC, University Hospital Birmingham, Edgbaston, Birmingham, West Midlands B15 2TT, UK (E-mail: Domenico.pagano@uhb.nhs.uk).

$0022-5223 / \$ 36.00$

Copyright (c) 2013 by The American Association for Thoracic Surgery

http://dx.doi.org/10.1016/j.jtcvs.2012.07.018 transmission, acute lung injury necessitating prolonged ventilation, perioperative myocardial infarction, and altered immunity. Cardiac surgery accounts for a large proportion of blood transfusion worldwide, almost $10 \%$ of all blood transfusions. ${ }^{7}$ The importance of blood conservation in cardiac surgery should therefore be considered, and at present the use of antifibrinolytic drugs remains a key part of this strategy.

The serine protease inhibitor aprotinin was a commonly used agent in this strategy, until the Blood Conservation Using Antifibrinolytics in a Randomized Trial (BART) study ${ }^{8}$ was terminated early in response to concerns of increased mortality associated with this agent. Since then, agents such as tranexamic acid and $\varepsilon$-aminocaproic acid have now become commonly used in blood conservation strategies in cardiac surgery. These agents have limited safety data and their use is not licensed in most countries.

BART has considerable design limitations, including the lack of placebo control. These limitations have been recently recognized by Health Canada (the department of the government of Canada responsible for the national public health) by reintroducing the use of aprotinin and calling for further safety trials. More recently, the European Medicine Agency has recommended the lifting of the restrictions on the use of aprotinin. ${ }^{9}$ We conducted a mixed treatment comparison (MTC) network meta-analysis to estimate the effects of aprotinin and alternative agents in reducing blood 


\section{Abbreviations and Acronyms \\ BART $=$ Blood Conservation Using \\ Antifibrinolytics in a Randomized Trial \\ MTC $=$ mixed treatment comparison}

loss during surgery and to examine the safety profiles of these agents. ${ }^{10}$

\section{MATERIALS AND METHODS}

Trials of aprotinin were identified and data were abstracted from the Cochrane meta-analysis by Henry and colleages. ${ }^{7}$ We conducted an MTC network meta-analysis to estimate the effects of aprotinin and alternative agents in reducing blood loss during surgery. ${ }^{10}$ There are two roles for MTC analysis. The first is to strengthen inference concerning the relative efficacies of a pair of treatments by including both "direct" and "indirect" comparisons. The other is to facilitate simultaneous inference regarding all treatments, for example to select the best treatment. ${ }^{10}$ MTC and network meta-analysis methods have become widely used in the evaluation of treatments and form an important part of the work of organizations such as the National Institute for Health and Clinical Excellence (NICE; http://www. nicedsu.org.uk/), which actively promotes the use of MTC methods.

We estimated the relative effects for different agents on the outcomes of all-cause mortality and return to the operating room for bleeding. We then conducted a supportive analysis of the effects of different agents with only the directly randomized trials and performed a number of analyses.

The first analysis was an MTC analysis of comparative trials that had an active comparator. The second was an MTC analysis extended to all randomized trials, including all placebo-controlled trials. The third compared the effects of antifibrinolytic agents both with placebo and with each other with respect to return to the operating room for bleeding. The lists of included trials for the analysis of mortality and return to the operating room for bleeding are provided in Tables 1 and 2, respectively.

\section{RESULTS}

The first analysis of comparative trials identified 17 trials comparing aprotinin with tranexamic acid, 5 trials comparing tranexamic acid with $\varepsilon$-aminocaproic acid, and 6 trials comparing aprotinin with $\varepsilon$-aminocaproic acid, as shown in Figure 1. The patient numbers for each treatment are shown in Table 3. As shown in Figure 2, no differences in mortality were demonstrated in this 3-way analysis, including comparing aprotinin versus tranexamic acid (odds ratio [OR], 0.83; 95\% confidence interval [CI], 0.48-1.83).

The second analysis of patients randomly allocated to treatment or control identified 88 trials. Figure 3 describes the network of these, the majority (54/88) of which were between aprotinin and control. The overall patient numbers analyzed are shown in Table 4, again with the greatest number being randomly allocated to aprotinin $(n=6284)$. Comparing all 3 agents with each other also demonstrated no differences in mortality between groups, as shown in Figure 4, including aprotinin versus tranexamic acid (OR, $0.73 ; 95 \% \mathrm{CI}, 0.45-1.21)$ and aprotinin versus placebo (OR, 1.11; 95\% CI, 0.75-1.53).

The third analysis compared the 3 antifibrinolytic agents with each other and with placebo, with respect to the outcome of reexploration for bleeding, as shown in Figure 5. All 3 agents were shown to be superior to placebo in reducing reexploration for bleeding: aprotinin OR, 2.58 (95\% CI, 1.91-3.70); tranexamic acid OR, 1.79 (95\% CI, 1.22-2.91); and $\varepsilon$-aminocaproic acid OR, $2.4(95 \% \mathrm{CI}$, 1.29-6.59). Aprotinin was shown to be numerically superior to tranexamic acid in reducing reexploration for bleeding, but this result was not statistically significant (aprotinin vs tranexamic acid OR, 1.4; 95\% CI, 0.94-2.08).

\section{DISCUSSION}

Aprotinin is the most studied antifibrinolytic agent for its use in cardiac surgery, and this MTC meta-analysis, in concordance with previous meta-analyses, ${ }^{7}$ supports the contention that it is safe and very effective in preventing reexploration for hemorrhage and blood transfusions. MTC analyses can provide useful estimates of treatment effects, which are derived across a network of interlocking randomized trials. They are particularly useful in the context of inclusion of trials with different comparators, either placebo or active therapies. Our MTC analysis advances the work of Henry and colleagues, ${ }^{7}$ who included all relevant trials but used only conventional direct meta-analysis to analyze results. There have been several meta-analyses of randomized trials involving aprotinin. Levi and coworkers in $1999^{11}$ demonstrated that aprotinin was associated with a reduction in mortality (OR, 0.55; 95\% CI, 0.34-0.90), a 2001 Cochrane review ${ }^{12}$ demonstrated that the use of aprotinin was not associated with increased mortality (OR, 0.87; 95\% CI, 0.63-1.9), and the latter finding was confirmed by Sedrakyan and associates ${ }^{13}$ in 2004 (OR, 0.96; 95\% CI, 0.65-1.4). Furthermore, aprotinin was associated with a reduction in risk of stroke (OR, 0.53; 95\% CI, 0.31 $0.90)$ and no increased mortality relative to other antifibrinolytic agents. $^{13}$

Despite these findings, the issue of safety with the use of aprotinin continued to be raised, particularly on the grounds that the majority of the published trials were small, were focused on reduction in blood transfused or reoperation for bleeding, and were not powered to detect a difference in mortality. ${ }^{14}$ The meta-analysis of these trials demonstrated significant and clinically important reductions in bleeding and reoperation rate with aprotinin, so a further trial of this agent versus placebo was not considered ethically justified. ${ }^{15}$ A further Cochrane review ${ }^{7}$ concluded that there were insufficient data to recommend definitively any antifibrinolytic agent rather than another, and with the cost of aprotinin being significantly greater than the other agents, BART was conceived. ${ }^{8}$

\section{BART and Its Aftermath}

BART was powered to detect a $50 \%$ reduction (from $6 \%$ to $3 \%$ ) in massive bleeding (including reoperation) and a $10 \%$ absolute risk reduction in allogeneic exposure to 
TABLE 1. Trials included in the analysis for mortality

\begin{tabular}{|c|c|c|c|c|c|}
\hline \multirow[b]{2}{*}{ Study by first author } & \multirow[b]{2}{*}{ Year } & \multicolumn{4}{|c|}{ No. of patients } \\
\hline & & Aprotinin & Control & TXA & EACA \\
\hline Alderman* & 1998 & 436 & 434 & & \\
\hline Alvarez* & 1995 & 49 & 51 & & \\
\hline Alvarez* & 2001 & 26 & 29 & & \\
\hline Andreasen* & 2004 & & 23 & 21 & \\
\hline Armellin* & 2001 & & 150 & 150 & \\
\hline Ashraf* & 1997 & 19 & 19 & & \\
\hline Bernet* & 1999 & 28 & & 28 & \\
\hline Bidstrup* & 1989 & 40 & 40 & & \\
\hline Bidstrup* & 1993 & 43 & 47 & & \\
\hline Bidstrup* & 2000 & 30 & 30 & & \\
\hline Blauhut & 1994 & 14 & 14 & 15 & \\
\hline Brown* & 1997 & & 30 & 60 & \\
\hline Casas* & 1995 & 47 & 51 & & \\
\hline Casati* & 1999 & 67 & & 70 & 66 \\
\hline Casati* & 2000 & 518 & & 522 & \\
\hline Cicekcioglu* & 2006 & 20 & 24 & & \\
\hline Coffey & 1995 & & 14 & 16 & \\
\hline Cohen & 1998 & 56 & 59 & & \\
\hline Colwell & 2007 & 175 & 178 & & \\
\hline Cosgrove* & 1992 & 113 & 56 & & \\
\hline D'Ambra* & 1996 & 141 & 71 & & \\
\hline Dalmau & 2000 & & & 42 & 42 \\
\hline Dalmau* & 2004 & 63 & & 64 & \\
\hline Del Rossi* & 1989 & & 180 & & 170 \\
\hline Desai* & 2009 & 38 & 37 & & \\
\hline Dietrich & 1992 & 902 & 882 & & \\
\hline Dietrich* & 1995 & 15 & 15 & & \\
\hline Dietrich* & 2008 & 110 & & 110 & \\
\hline Dignan* & 2001 & 101 & 99 & & \\
\hline Diprose* & 2005 & 60 & 60 & 60 & \\
\hline Dryden & 1997 & & 19 & 22 & \\
\hline Englberger* & $2002 a$ & 22 & 25 & & \\
\hline Englberger* & $2002 b$ & 15 & 14 & & \\
\hline Feindt & 1994 & 10 & 10 & & \\
\hline Fergusson* & 2008 & 779 & & 769 & 780 \\
\hline Golanski & 2000 & 30 & 24 & & \\
\hline Gott & 1998 & 109 & 112 & & \\
\hline Green & 1995 & 48 & 36 & & \\
\hline Greilich & 2009 & 26 & 27 & & 25 \\
\hline Hardy* & 1993 & 22 & 22 & & \\
\hline Hardy* & 1998 & & 45 & 43 & 46 \\
\hline Hayashida & 1997 & 110 & 57 & & \\
\hline Hekmat & 2004 & 60 & & 58 & \\
\hline Ickx & 2006 & 24 & & 27 & \\
\hline Jamieson & 1997 & 24 & 36 & & \\
\hline Jares* & 2003 & & 25 & 22 & \\
\hline Jimenez* & 2007 & & 26 & 24 & \\
\hline Karski & 2005 & & 165 & 147 & \\
\hline Katoh & 1997 & & 31 & 62 & \\
\hline Katsaros* & 1996 & & 106 & 104 & \\
\hline Kipfer* & 2003 & 15 & 15 & & \\
\hline Kluger* & 2003 & & 30 & & 58 \\
\hline Koster* & 2004 & 100 & 100 & & \\
\hline Kueppper* & 2003 & 60 & 59 & & \\
\hline
\end{tabular}

(Continued)
TABLE 1. Continued

\begin{tabular}{|c|c|c|c|c|c|}
\hline \multirow[b]{2}{*}{ Study by first author } & \multirow[b]{2}{*}{ Year } & \multicolumn{4}{|c|}{ No. of patients } \\
\hline & & Aprotinin & Control & TXA & EACA \\
\hline Kuitunen* & 2005 & 20 & 20 & 20 & \\
\hline Kunt* & 2005 & 40 & 46 & & \\
\hline Landymore & 1997 & 48 & & 56 & 44 \\
\hline Lass* & 1995 & 51 & 47 & & \\
\hline Later* & 2009 & 96 & 103 & 99 & \\
\hline Leijdekkers* & 2006 & 16 & 19 & & \\
\hline Lemmer* & 1996 & 526 & 178 & & \\
\hline Lemmer* & 1994 & 108 & 108 & & \\
\hline Levy* & 1995 & 215 & 72 & & \\
\hline Liu* & 1993 & 20 & 20 & & \\
\hline Maccario & 1994 & 61 & 32 & & \\
\hline Maddali* & 2007 & & 111 & 111 & \\
\hline Mehr-Aein* & 2007 & & 33 & 33 & \\
\hline Misfeld & 1998 & 14 & 14 & 14 & \\
\hline Mohr* & 1992 & 34 & 16 & & \\
\hline Mongan* & 1998 & 75 & & 75 & \\
\hline Moran* & 2000 & 28 & 14 & & \\
\hline Murphy* & 2006 & & 50 & 50 & \\
\hline Norman & 2009 & 11 & 9 & & \\
\hline Nuttal* & 2000 & 45 & 45 & 45 & \\
\hline Rocha & 1994 & 28 & 28 & & \\
\hline Rodrigus* & 1996 & 46 & 47 & & \\
\hline Royston & 1987 & 11 & 11 & & \\
\hline Santos* & 2006 & & 31 & 29 & \\
\hline Schweizer* & 2000 & 28 & 29 & & \\
\hline Shore-Lesserson* & 1996 & & 13 & 17 & \\
\hline Stammers & 1997 & 8 & 12 & & \\
\hline Swart & 1994 & 49 & 49 & & \\
\hline Trinh-Duc & 1992 & 29 & & & 27 \\
\hline Van der Linden & 2005 & 37 & 38 & & \\
\hline Vander-Salm* & 1996 & & 50 & & 51 \\
\hline Wei & 2006 & 36 & 40 & & \\
\hline Wong* & 2000 & 39 & & 38 & \\
\hline Zabeeda & 2002 & & 25 & 25 & \\
\hline Sum & & 6284 & 4887 & 3048 & 1309 \\
\hline
\end{tabular}

any blood products (from $50 \%$ to $40 \%$ ) in patients treated with aprotinin as compared with $\varepsilon$-aminocaproic acid or tranexamic acid during high-risk cardiac surgical procedures. BART was not designed or powered to assess mortality outcome differences among the 3 agents. The study was terminated prematurely in the wake of concerns of increased mortality associated with aprotinin.

This study, however, had a number of important methodologic limitations. The patient population was heterogeneous, because the trial enrolled patients undergoing various operations, and often reoperations or procedures including the aortic root and adult congenital heart procedures that are known to carry differing operative risks. Despite this overwhelming influence of procedure and patients characteristics on mortality, there was no stratification of 
TABLE 2. Additional trials included in the analysis for reexploration for bleeding

\begin{tabular}{|c|c|c|c|c|c|}
\hline \multirow[b]{2}{*}{ Study by first author } & \multirow[b]{2}{*}{ Year } & \multicolumn{4}{|c|}{ No. of patients } \\
\hline & & Aprotinin & Control & TXA & EACA \\
\hline Asimakopoulos & 2000 & 8 & 10 & & \\
\hline Bennett-Guerrero & 1997 & & 99 & & 105 \\
\hline Bert & 2008 & 25 & 25 & & \\
\hline Bidstrup & 1990 & 26 & 18 & & \\
\hline Boldt & 1994 & 20 & 20 & & \\
\hline Casati & 2004 & & 50 & 52 & \\
\hline Deleuze & 1991 & 30 & 30 & & \\
\hline Demeyere & 2006 & 20 & 20 & 20 & \\
\hline Dietrich & 1990 & 19 & 20 & & \\
\hline Hardy & 1997 & 26 & 26 & & \\
\hline Horrow & 1991 & & 45 & 28 & \\
\hline Karski & 1995 & 100 & & 50 & \\
\hline Kuitunen & 2006 & & 15 & 15 & \\
\hline Laub & 1994 & 16 & 16 & & \\
\hline Mansour & 2004 & 20 & 20 & 20 & \\
\hline Menichetti & 1996 & 24 & 24 & 24 & 24 \\
\hline Nurozler & 2008 & 25 & 26 & & \\
\hline Parvizi & 2007 & 81 & 81 & & \\
\hline Penta de Pepo & 1995 & 15 & 15 & 15 & 15 \\
\hline Pleym & 2003 & & 39 & 40 & \\
\hline Pugh & 1995 & 25 & 15 & 25 & \\
\hline Rao & 1999 & & 15 & & 15 \\
\hline Ray & 1997 & 21 & 23 & & \\
\hline Ray & 1999 & 100 & 50 & & \\
\hline Ray & 2001 & 49 & & & 51 \\
\hline Rossi & 1997 & 21 & 24 & & \\
\hline Tabuchi & 1994 & 20 & 20 & & \\
\hline Taggart & 2003 & 36 & 34 & & \\
\hline Uozaki & 2001 & & 6 & 6 & \\
\hline
\end{tabular}

EACA, ع-Aminocaproic acid; TXA, tranexamic acid.

treatment allocation by procedure, patient risk profile, or participating center. The investigators performed a logistic regression adjustment for confounding factors, including operative and comorbid conditions, but the results of this

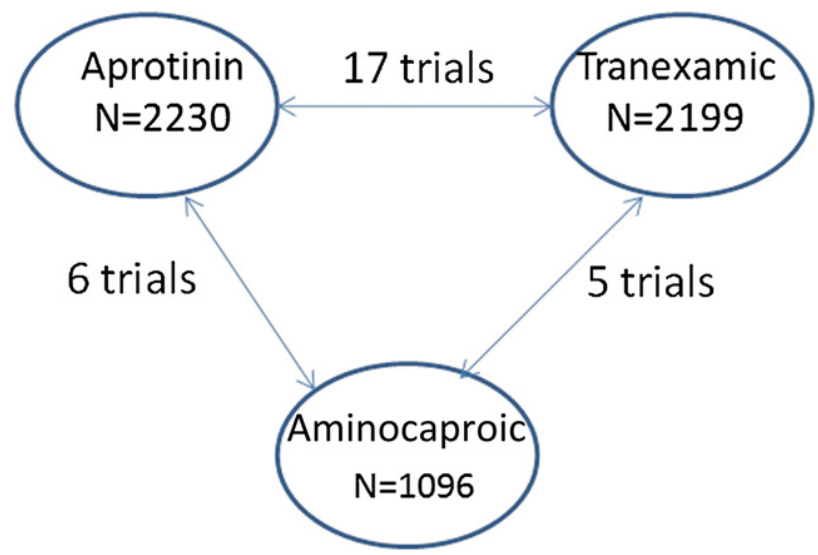

FIGURE 1. Trials network diagram of the trials examined in the analysis of comparative trials.
TABLE 3. Patient numbers for each treatment allocation in the analysis of comparative trials

\begin{tabular}{lcc}
\hline & N & Deaths \\
\hline Aprotinin & 2230 & 72 \\
Tranexamic acid & 2199 & 54 \\
$\varepsilon$-Aminocaproic acid & 1096 & 40 \\
\hline
\end{tabular}

analysis were not published. The reported mortality (not adjusted for procedure) in the aprotinin arm was $3.2 \%(25 /$ $779)$, versus $1.3 \%(10 / 769)$ in the tranexamic acid arm and $1.7 \%(13 / 780)$ in the $\varepsilon$-aminocaproic acid arm. Although nominal ORs and CIs were calculated for these groups, these do not allow for the repeated analyses that reduce the level of significance from the preset one ( $\alpha$ spending), thus rendering the results statistically nonsignificant. Health Canada has also reviewed BART again and, highlighting some irregularities in reclassification of primary outcomes, has reissued guidance that the benefit of aprotinin outweighs the risk. ${ }^{16}$

After BART, a further retrospective database analysis was conducted at the request of the manufacturer. ${ }^{17}$ It has previously been demonstrated that retrospective analysis of patients selectively treated with aprotinin is difficult to perform, because aprotinin is typically used when a patient is perceived to be at greater operative risk, a phenomenon called "confounding by indication." This confounding is difficult to account for statistically, and the outcomes of patients so selected to receive aprotinin thus may be perceived as being inferior, a difference that has not been demonstrated in patients treated in a nonselective manner. ${ }^{18}$ This large, observational study reflects such findings. Patients in the aprotinin cohort were more than twice as likely to have undergone reoperative surgery, and, although this study was labeled as a study of patients undergoing coronary artery bypass grafting, $25.2 \%$ of patients in the aprotinin arm underwent concomitant valve surgery, compared with $18 \%$ in the tranexamic acid group. Patients in the aprotinin group were also older, had a greater incidence of peripheral arterial disease, had a greater incidence of chronic kidney disease, were more likely to undergo complex coronary artery bypass grafting surgery, and were more likely to have required treatment for heart failure. Once the analysis took into account the surgeons' selective bias with an instrumental variable analysis, no significant adverse effect of aprotinin on survival was demonstrated.

A further meta-analysis of 11 epidemiologic studies ${ }^{19}$ demonstrated no increase of in-hospital mortality with aprotinin but did show a reduced late survival. They also demonstrated, however, that aprotinin was used with procedures requiring a longer bypass time, which itself is a marker of complex surgery and in this study was a predictor of adverse events. 


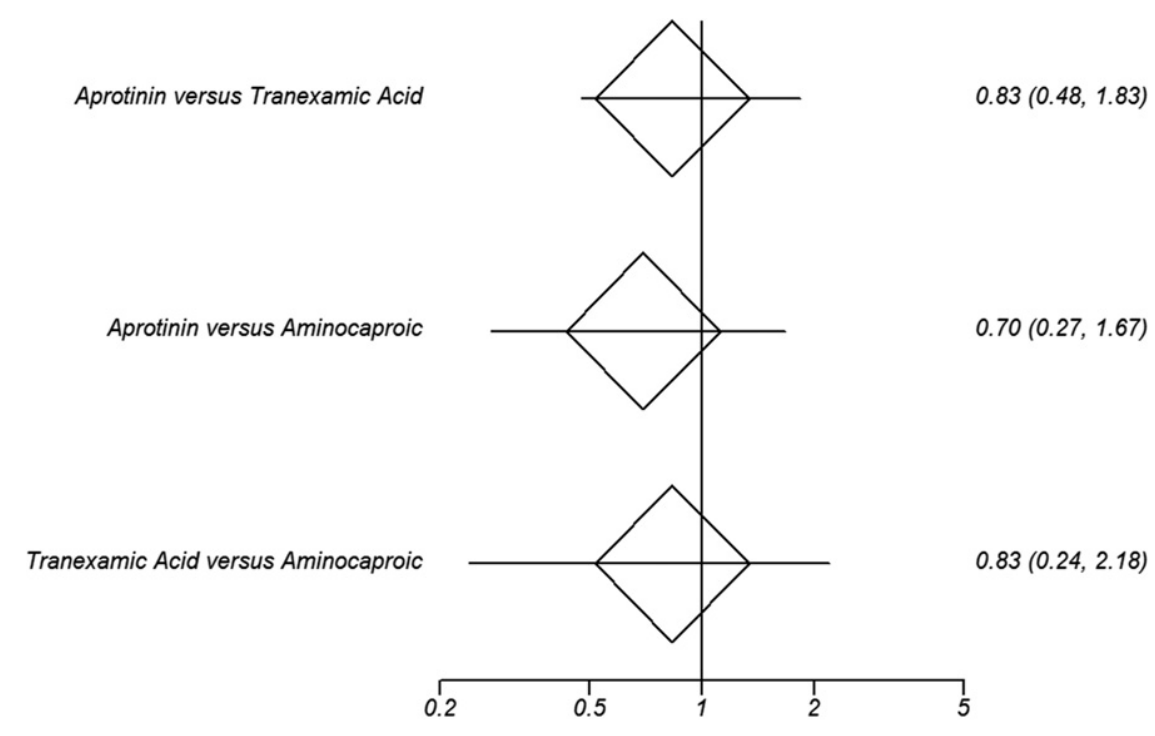

Note odds ratio $<1$ favours the second listed treatment

FIGURE 2. Differences in mortality between treatments. Odds ratios are given, with $95 \%$ confidence intervals in parentheses. An odds ratio less than 1 favors the second listed treatment.

Historical data suggest that reoperations for bleeding can be associated with increased mortality. ${ }^{20}$ The issue has been raised that the reduction in these complications seen with aprotinin has not translated into improved survival. It is possible, however, that this is because more contemporary data show similar early survivals for patients who have significant bleeding and those who do not. ${ }^{3}$ Furthermore, more recently, the withdrawal of aprotinin at the time when this agent was thought to increase mortality has not resulted in any improvement in early postoperative outcomes; rather, there has been an increase in the use of blood products. ${ }^{21}$ Bleeding after cardiac surgery can be treated with surgical

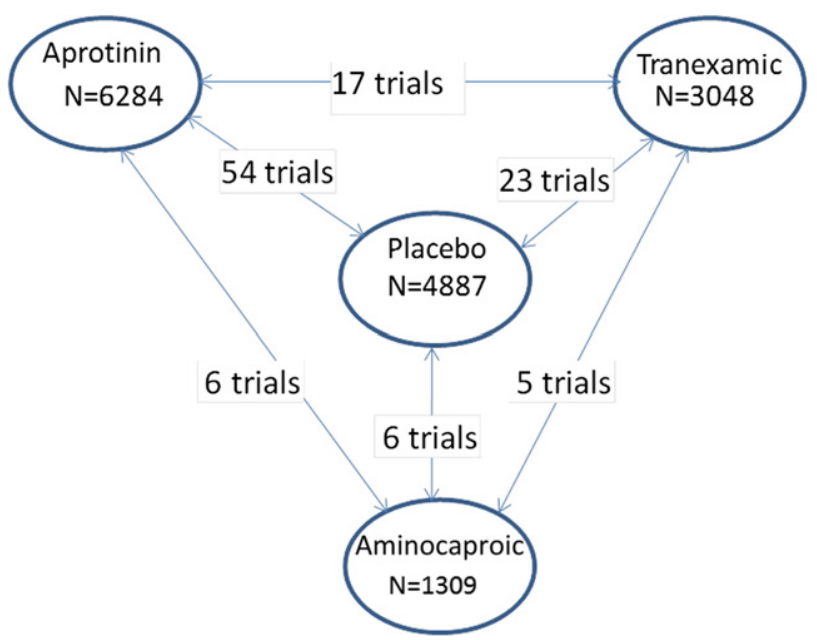

FIGURE 3. Trials network diagram of all randomized trials contributing to mortality analysis. reexploration and transfusion of blood and blood products, and this inevitably leads to a significant increase in resource requirement, especially of blood bank and critical care resources, and may still result in late morbidity.

The story surrounding aprotinin may well have become more interesting than the drug itself, and there are many lessons to be learned from this for all stakeholders. Investigators of new therapeutic agents, conducting several small studies underpowered for mortality end points over a 30year period have not unequivocally demonstrated its safety, and reports of early graft failure and renal impairment presumed to be secondary to the prothrombotic effects of antifibrinolytic agents have not been adequately investigated. Drug regulatory bodies have responded with knee-jerk reactions to small, poorly designed trials and high-profile epidemiologic studies, despite the significant weight of the previous literature. Many patients have received aprotinin, some of whom may have actually derived benefit from the drug but now may either seek litigation or remain concerned about their own outcomes. We have not seen any improvements in clinical outcomes since the use of aprotinin has been restricted, but there has been an increase in use of

TABLE 4. Patient numbers for each treatment and control in analysis of all randomized trials

\begin{tabular}{lccc}
\hline \multicolumn{1}{c}{ Agent } & Trials & N & Deaths \\
\hline Aprotinin & 67 & 6284 & 177 \\
Tranexamic acid & 35 & 3048 & 62 \\
$\varepsilon$-Aminocaproic acid & 11 & 1309 & 44 \\
Placebo & 75 & 4887 & 110 \\
\hline
\end{tabular}




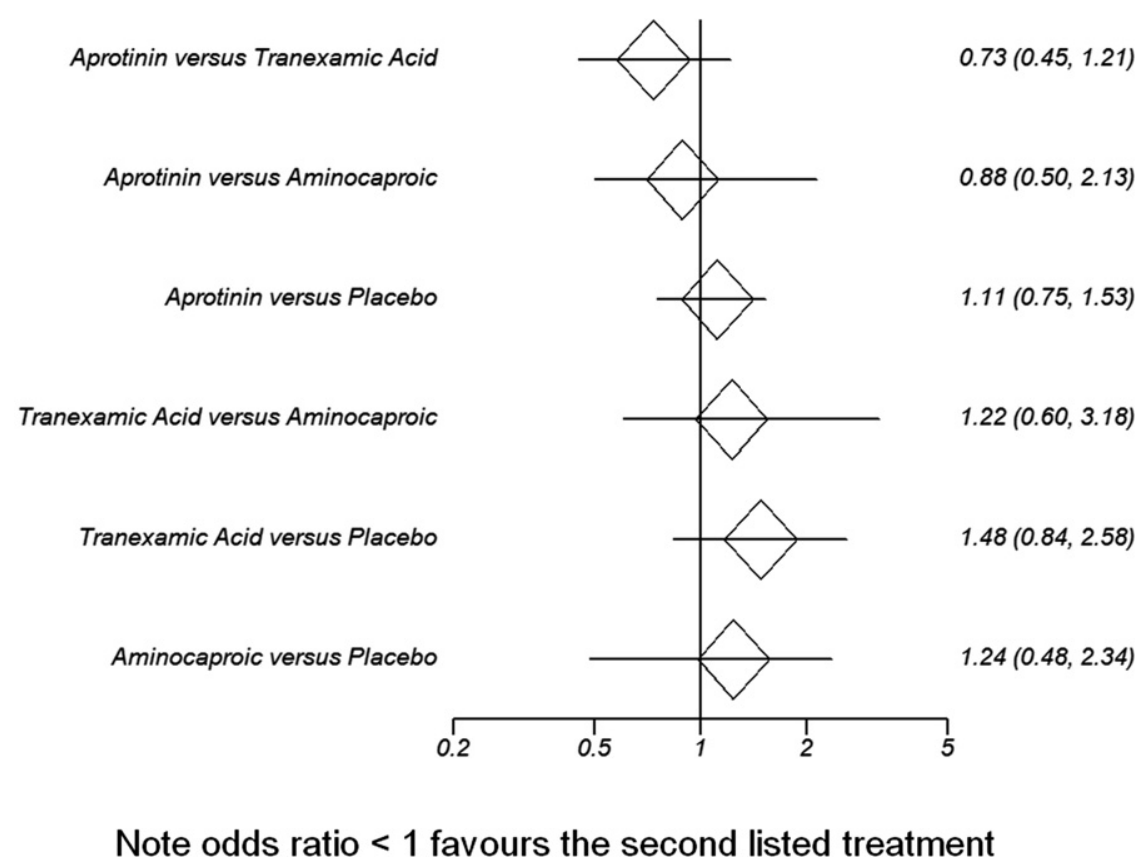

FIGURE 4. Comparison of active agents and placebo for the outcome of all-cause mortality. Odds ratios are given with $95 \%$ confidence intervals in parentheses. An odds ratio less than 1 favors the second listed treatment.

blood products. ${ }^{21}$ The patent for aprotinin has now expired and it has now become another cheap generic drug. As such, the appetite for running the large clinical safety trial that should have been performed initially will now be lessened.

\section{CONCLUSIONS}

This meta-analysis, which includes data from BART, demonstrates no increase in the risk of in-hospital mortality for patients treated with aprotinin relative to either placebo or other antifibrinolytic agents. This is in line with the updated Cochrane review, which has also demonstrated no increased risk of aprotinin relative to placebo and no increased risks of myocardial infarction, stroke, and renal dysfunction or failure. Most studies in our meta-analysis include only patients undergoing coronary artery bypass grafting. The evidence for higher-risk procedures is lacking

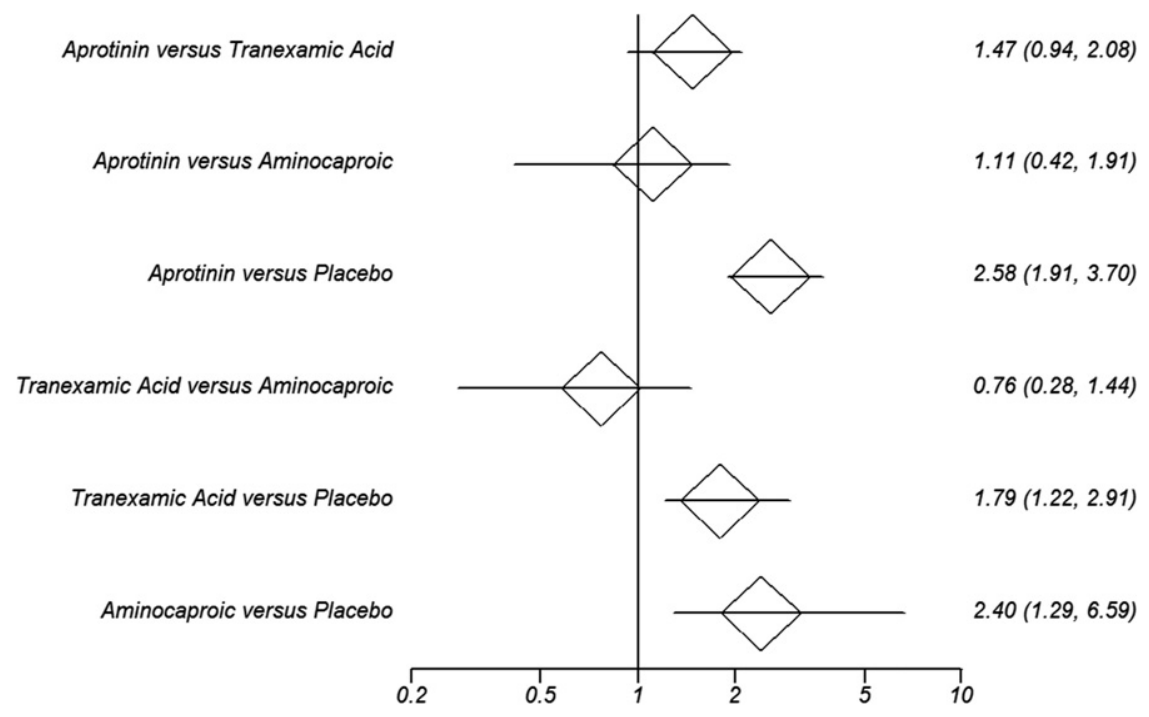

Note odds ratio $<1$ favours the second listed treatment

FIGURE 5. Comparison of effects of different agents and placebo on the outcome of return to the operating room for bleeding. Odds ratios are given with $95 \%$ confidence intervals in parentheses. An odds ratio less than 1 favors the second listed treatment. 
for all antifibrinolytic agents. Our analysis supports the recent recommendations from Health Canada and the European Medicine Agency.

\section{References}

1. Bridgewater B, Keogh B. Sixth National Adult Cardiac Surgical Database report, demonstrating quality. Henley-on-Thames, UK: Dendrite Clinical Systems; 2009.

2. Vivacqua A, Koch CG, Yousuf AM, Nowicki ER, Houghtaling PL, Blackstone EH, et al. Morbidity of bleeding after cardiac surgery: is it blood transfusion, reoperation for bleeding, or both? Ann Thorac Surg. 2011;91:1780-90.

3. Karthik S, Grayson AD, McCarron EE, Pullan DM, Desmond MJ. Reexploration for bleeding after coronary artery bypass surgery: risk factors, outcomes, and the effect of time delay. Ann Thorac Surg. 2004;78:527-34; discussion 34.

4. Scott BH, Seifert FC, Grimson R. Blood transfusion is associated with increased resource utilisation, morbidity and mortality in cardiac surgery. Ann Card Anaesth. 2008;11:15-9.

5. Kuduvalli M, Oo AY, Newall N, Grayson AD, Jackson M, Desmond MJ, et al. Effect of peri-operative red blood cell transfusion on 30-day and 1-year mortality following coronary artery bypass surgery. Eur J Cardiothorac Surg. 2005;27: 592-8.

6. NHS Blood and Transplant. Annual review: saving and improving lives. Walford, UK: National Health Service Blood Transfusion Review Board; 2009/2010.

7. Henry DA, Carless PA, Moxey AJ, O'Connell D, Stokes BJ, Fergusson DA, et al. Anti-fibrinolytic use for minimising perioperative allogeneic blood transfusion. Cochrane Database Syst Rev. 2011;3:CD001886.

8. Fergusson DA, Hébert PC, Mazer CD, Fremes S, MacAdams C, Murkin JM, et al. A comparison of aprotinin and lysine analogues in high-risk cardiac surgery. N Engl J Med. 2008;358:2319-31.

9. European Medicines Agency [Internet]. London: The Agency; c1995-c2012 [updated 2012 Feb 17; cited 2012 May 2]. European Medicines Agency recommends lifting suspension of aprotinin. Available from: http://www.ema.europa.eu/ema/ index.jsp?curl=pages/news_and_events/news/2012/02/news_detail_001447.jsp $\& \mathrm{mid}=\mathrm{WCOb} 01 \mathrm{ac} 058004 \mathrm{~d} 5 \mathrm{c} 1 \& \mathrm{jsenabled}=$ true .
10. Lu G, Ades AE. Combination of direct and indirect evidence in mixed treatment comparisons. Stat Med. 2004;23:3105-24.

11. Levi M, Cromheecke ME, de Jonge E, Prins MH, de Mol BJ, Briët E, et al. Pharmacological strategies to decrease excessive blood loss in cardiac surgery: a meta-analysis of clinically relevant endpoints. Lancet. 1999;354:1940-7.

12. Henry DA, Moxey AJ, Carless PA, O'Connell D, McClelland B, Henderson KM, et al. Anti-fibrinolytic use for minimising perioperative allogeneic blood transfusion. Cochrane Database Syst Rev. 2001;1:CD001886.

13. Sedrakyan A, Treasure T, Elefteriades JA. Effect of aprotinin on clinical outcomes in coronary artery bypass graft surgery: a systematic review and meta-analysis of randomized clinical trials. J Thorac Cardiovasc Surg. 2004; 128:442-8.

14. Rosén M. The aprotinin saga and the risks of conducting meta-analyses on small randomised controlled trials-a critique of a Cochrane review. BMC Health Serv Res. 2009;9:34

15. Young C, Horton R. Putting clinical trials into context. Lancet. 2005;366:107-8.

16. Health Canada [Internet]. Ottawa: Health Canada; c2012 [updated 2011 Sep 21; cited 2011 Oct 10]. Health Canada decision on Trasylol (aprotinin). Available from: http://www.hc-sc.gc.ca/ahc-asc/media/advisories-avis/_2011/2011_ 124-eng.php.

17. Schneeweiss S, Seeger JD, Landon J, Walker AM. Aprotinin during coronary-artery bypass grafting and risk of death. $N$ Engl J Med. 2008; 358:771-83.

18. Pagano D, Howell NJ, Freemantle N, Cunningham D, Bonser RS, Graham TR, et al. Bleeding in cardiac surgery: the use of aprotinin does not affect survival. J Thorac Cardiovasc Surg. 2008;135:495-502.

19. Gagne JJ, Griesdale DE, Schneeweiss S. Aprotinin and the risk of death and renal dysfunction in patients undergoing cardiac surgery: a meta-analysis of epidemiologic studies. Pharmacoepidemiol Drug Saf. 2009;18:259-68.

20. Hall TS, Brevetti GR, Skoultchi AJ, Sines JC, Gregory P, Spotnitz AJ. Re-exploration for hemorrhage following open heart surgery differentiation on the causes of bleeding and the impact on patient outcomes. Ann Thorac Cardiovasc Surg. 2001;7:352-7

21. DeSantis SM, Toole JM, Kratz JM, Uber WE, Wheat MJ, Stroud MR, et al. Early postoperative outcomes and blood product utilization in adult cardiac surgery: the post-aprotinin era. Circulation. 2011;124(11 Suppl):S62-9.

\section{COMMENTARY}

\section{Facts, opinions, and conclusions: Aprotinin brings out all of these}

\section{Victor A. Ferraris, MD, PhD}

In general, an opinion is a subjective belief, and is the result of emotion or interpretation of facts. An opinion may be

From the Department of Cardiothoracic Surgery, University of Kentucky, Lexington, Ky.

Disclosures: Author has nothing to disclose with regard to commercial support.

Received for publication July 8, 2012; revisions received Aug 7, 2012; accepted for publication Sept 13, 2012; available ahead of print Oct 11, 2012.

Address for reprints: Victor A. Ferraris, MD, PhD, Department of Cardiothoracic Surgery, A301, Kentucky Clinic, 740 South Limestone, Lexington, KY 40536-0284 (E-mail: Ferraris@earthlink.net).

J Thorac Cardiovasc Surg 2013;145:240-2

0022-5223/\$0.00

Published by Elsevier Inc. on behalf of The American Association for Thoracic Surgery

http://dx.doi.org/10.1016/j.jtcvs.2012.09.026 supported by an argument, although people draw opposing opinions from the same set of facts. Almost all cardiac surgeons have an opinion about the use of aprotinin. These opinions range from strong support for drug use to adamant insistence that the drug causes harm. The facts that the supporters and detractors use to form their opinions are the same. Only conclusions differ.

\section{WHAT ARE THE FACTS?}

Fact 1: Aprotinin Reduces Bleeding, Blood Transfusion, and Reoperation for Bleeding in Patients Having a Variety of Cardiac Operations

There can be little doubt of this fact. In developing practice guidelines about blood conservation for the Society of 